\section{En sur udfordring for bevaring af bibliotekets samlinger}

af konservator Birgit Vinther Hansen, Det Kongelige Bibliotek

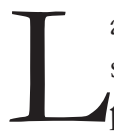
angt den største del af vores skriftlige kulturarv er nedfældet på papir - fra sen middelalder og frem til i dag, hvor større og større dele kun findes digitalt. Biblioteker og arkiver verden over har, som Det Kongelige Bibliotek, en forpligtelse til at bevare den indsamlede kulturarv for eftertiden, men det har vist sig at være en stor udfordring hvad angår papiret fra begyndelsen af 1800-tallet til langt op i det 20. århundrede.

På grund af nye fremstillings- metoder i forbindelse med industrialisering af papirfabrikationen er en meget stor del af vores papir nemlig syre- og træholdigt og nedbrydes derfor forholdsvist hurtigt.

På Det Kongelige Bibliotek er vi derfor så småt begyndt at støde på bøger og håndskrifter fra 1800- og 1900-tallet, som i dag er så nedbrudte, at de ikke længere kan tåle fysisk håndtering, og dermed ikke længere kan stilles fysisk til rådighed for borgerne.

Nedbrydningen skyldes, at det høje syreindhold i papiret (ved almindelig stuetemperatur) forårsager kemiske splitninger, så papiret bliver svagere og svagere, ender med at blive mere og mere gulbrunt og til sidst bliver så sprødt, at det falder fra hinanden ved almindelig håndtering. Jo surere papiret er, des hurtigere går nedbrydningen. I fig. 1 ses et eksempel på et avispapir fra 1946, som uden videre knækker, hvis man tager fat i det.

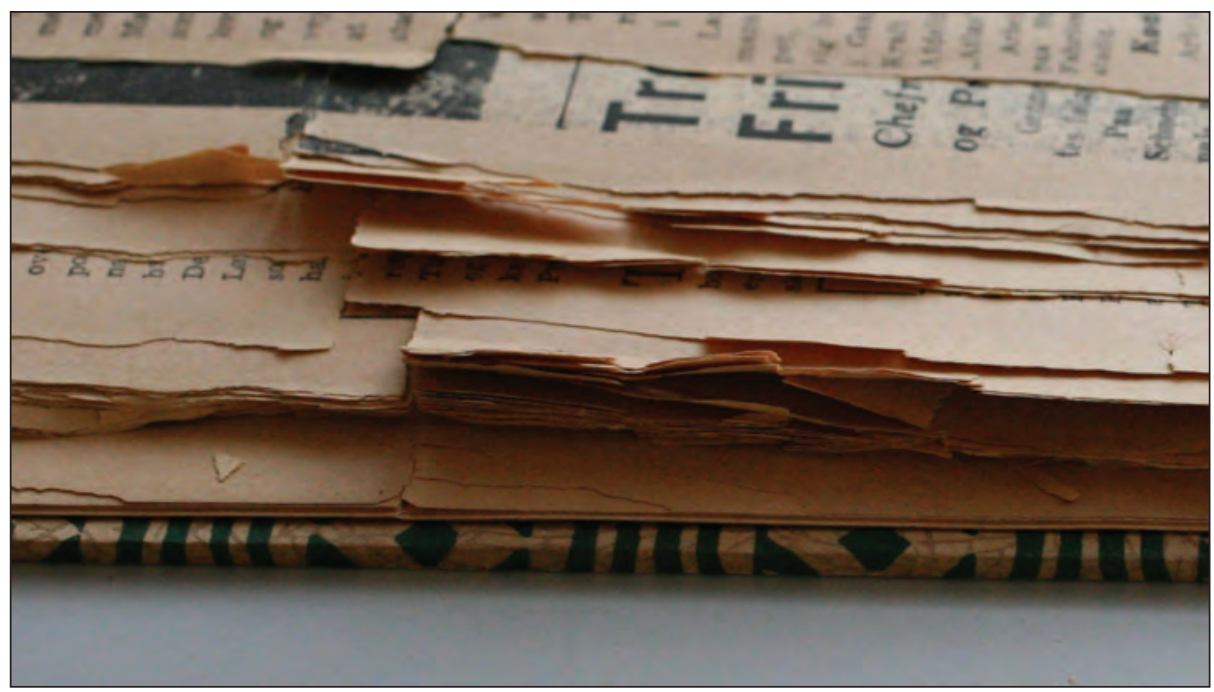

Fig. 1. Sprodt papir. Her avisen Information fra 1946 (Det Kongelige Bibliotek). 
Når en meget stor del af vores skriftlige kulturarv i biblioteker, arkiver og privateje har en forholdsvis kort anvendelig levetid i sin originale fysiske form, så vedkommer det os alle sammen, da det drejer sig om enestående værker - eksempelvis i form af bøger $i$ et enkelt bevaret eksemplar, nationale arkivalier, forfatteres håndskrifter, noder, kort og kunst.

\section{Papirfremstilling og holdbarhed}

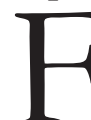
Tor industrialiseringen fremstillede man traditionelt det håndgjorte papir af indsamlede, langfibrede klude af hør og bomuld. Det håndgjorte papir (fig. 2) blev til skrivebrug efterli-

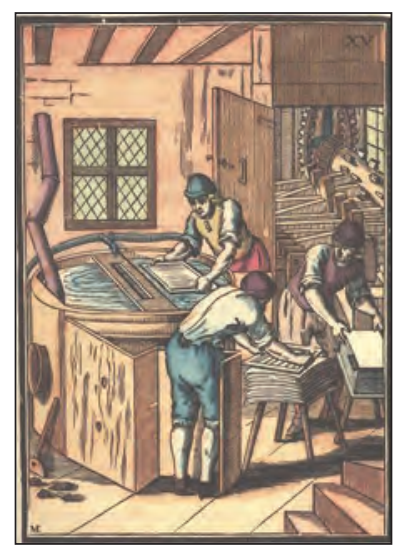

Fig. 2. Den opslammede fibermasse samles til et papirark. ved bjaclp af en trådform. Senere limes papiret med gelatine. Fra Elias Porcelius' Curioser Spiegel (1689).

met med gelatine, hvilket resulterede i en meget stærk og langtidsholdbar papirkvalitet, som under gode betingelser kan bevares i tusinder af år.

Med industrialisering af papirproduktionen og kraftig stigende efterspørgsel blev der i første halvdel af 1800-tallet overalt i den vestlige verden mangel på råstoffet klude. I Danmark blev det i 1825 endda forbudt ved lov at eksportere klude ud af Danmark, da der var brug for det til dansk papirfremstilling. ${ }^{1}$ Kludemanglen bevirkede, at der blev eksperimenteret med anvendelse af mange andre fiberkilder - enten sammen med kludene for at strække kludepapirmassen eller for helt at erstatte denne. I Danmark blev halmmasse anvendt i stor stil i perioden 1850-90, men på længere sigt blev det træmassen, der sejrede som fiberråstof. Tilsætningen af halm og træmasse medførte en forringet papirkvalitet, da fibrene herfra er kortere end det langfibrede hør og bomuld, og desuden indeholder en stor andel sur lignin, der i træet fungerer som en form for lim i den oprindelige fiberstruktur, men i papiret medvirker til forsuring.

Sammen med papirmaskinens indtog - i Danmark i 1829 - introduceredes en vegetabilsk harpikslim tilsat direkte til papirmassen, da papiret nu blev produceret i løbende baner, og ikke længere kunne efterlimes arkvis. Harpiks fungerer kun som fiberlimstof $i$ et surt miljø, så det er nødvendigt at tilsætte store mængder alun til papirmassen for at justere surhedsgaden ( $\mathrm{pH}$-værdien) til rette niveau. Limtypen bliver derfor i Danmark naturligt kaldt surlimning. Med surlimning kan det ikke undgås, at det færdige stykke papir ender med at have et forholdsvis højt syreindhold (det samme som en lav pH-værdi). Omkring 1870'erne erstattedes den ellers naturudvundne alun af en industrielt fremstillet alun, som var langt mere koncentreret, og desuden indeholdt en del svovlsyre, hvilket bidrog til, at datidens papirkvaliteter forsuredes yderligere.

En stor del af papiret var i slutningen af 1800-tallet hermed 
både surlimet og indeholdt forholdsvis kortfibret, ligninholdigt fibermateriale. Således skete på forholdsvis kort tid en meget stor kvalitetsændring af papirindustriens produkter, som sammen med en meget hård indbyrdes konkurrence i dansk papirindustri førte til en katastrofal dårlig papirkvalitet. Alle papirproducenter var ved at gå fallit og de havde problemer med anvendelsen af træfibrerne. ${ }^{2}$ Den hårde konkurrence på markedet afsluttedes brat i 1889, hvor De forenede Papirfabrikker A/S (DfP) blev stiftet og man specialiserede sig på de enkelte fabrikker. I fig. 3 ses det muligvis første billede af en papirmaskine i Danmark. Maskinen er fra 1894 og indvarsler nye og bedre papirkvaliteter.

Man blev tidligt opmærksom på de nye papirtypers ringe fysiske kvaliteter, men tillagde ikke den sure limning nævneværdig indflydelse på kvaliteten. I 1930'erne blev det dog endeligt klart, at et højt syreindhold i papiret spiller en afgørende rolle for papirets holdbarhed, men på grund af surlimningens lave produktionsomkostninger var det desværre ikke muligt for mere holdbare ikke-sure papirkvaliteter at konkurrere på markedet. ${ }^{3}$

En basisk limning blev efterfølgende udviklet i 1950'erne, og der blev siden udviklet en international standard ${ }^{4}$ for krav til papirets holdbarhed. I løbet af 1970'erne vandt neutralt eller alkalisk limet, papir terræn, og fra 1980’erne blev det dominerende på markedet. Papiret, som vi anvender i dag, har dermed igen generelt en god holdbarhed med en forventet levetid på mere end tusind år for de bedste kvaliteter. ${ }^{5}$

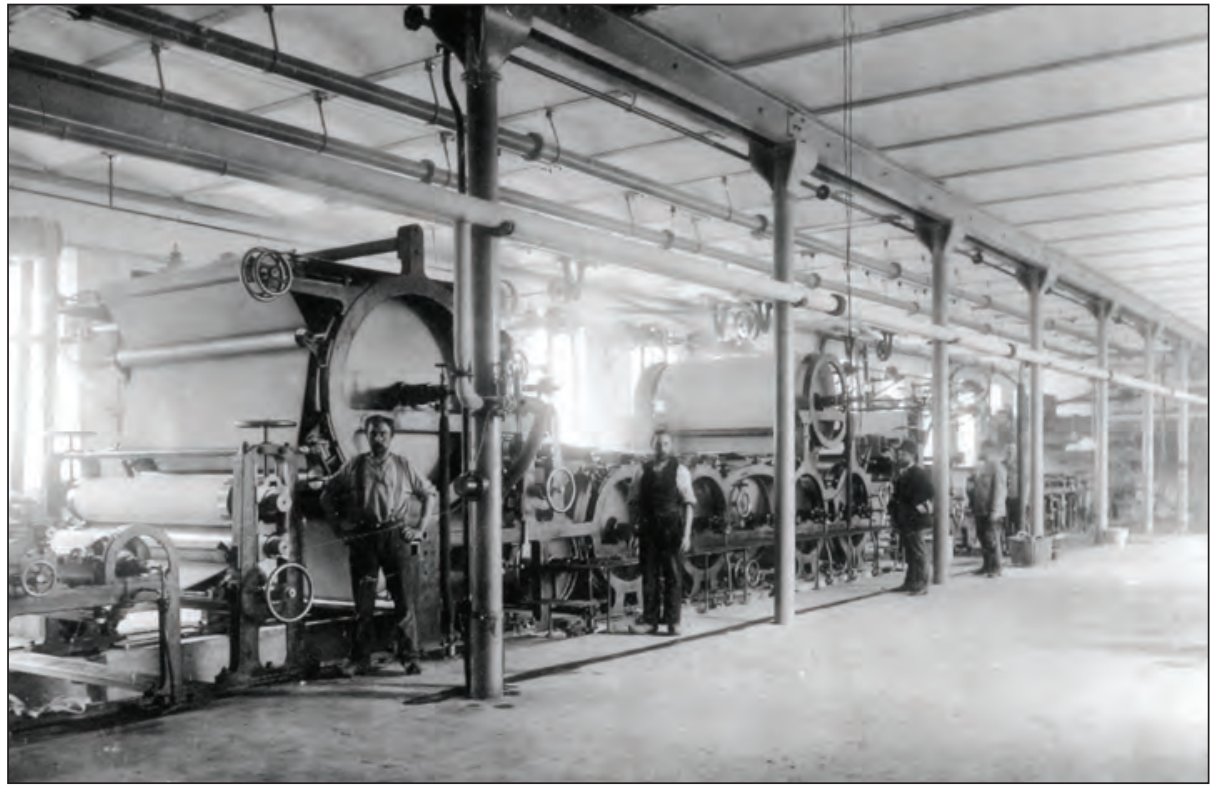

Fig. 3. Silkeborg Papirfabriks nye papirmaskine 1894. Billedet viser kalander (glitte) og torreparti med 'den våde ende' i baggrunden (Papirmuseet Bikuben). 
Herved opstår den paradoksale situation, at mens håndgjort kludepapir fra for industrialiseringen kan holde $\mathrm{i}$ tusindvis af år under gode opbevaringsforhold, så har papir fremstillet mellem 1850 og slutningen af 1970'erne typisk en langt, langt kortere levetid.

Ved køb af papir i dag vil man som regel kunne se på varedeklarationen om det lever op standarden ISO 9706 - et bevis for at det er langtidsholdbart. Det kan også ses på indersiden af omslaget af denne publikation. Aviser og billigbøger er dog stadig eksempler på materiale, som er trykt på papir fremstillet af ligninholdigt træslib, og som hurtigt nedbrydes.

\section{Hvor galt står det til i Det Kongelige Biblioteks samlinger?}

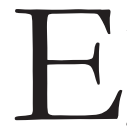

$\mathrm{n}$ nærmere undersøgelse af samlingernes alder har vist, at godt $70 \%$ (40 ud af 60 hyldekilometer) af bibliotekets bevaringsværdige bøger, kort og håndskrifter er fremstillet i den kritiske periode mellem 1800 og 1985. To tredjedele af bibliotekets beholdning er således fremstillet i papirfremstillingens "mørke" årtier, selvom bibliotekets papirbaserede samlinger strækker sig helt tilbage til middelalderen.

For at få belyst mulighederne for bevaring af de store mængder surt papir i de statslige samlinger, nedsatte Kulturministeriet i 2004 en arbejdsgruppe under Biblioteksstyrelsen (i dag Styrelsen for Bibliotek og Medier), som skulle undersøge, hvor meget bevaringsværdigt surt papir der var i samlingerne, og hvorvidt en såkaldt masseafsyring af samlingerne kunne anbefales som bevaringsstrategi. ${ }^{6}$ Det Kongelige Bibliotek var repræsenteret i udvalget og bidrog dermed aktivt til udvalgets undersøgelser og anbefaling omkring bevaring af surt papir i Danmark.

I den forbindelse gennemførtes i 2006 en stikprøveundersøgelse ${ }^{7}$ i bibliotekets samlinger fra 1800-1985, hvor vi blandt andet undersøgte surheds- og nedbrydningsgrad (målt som

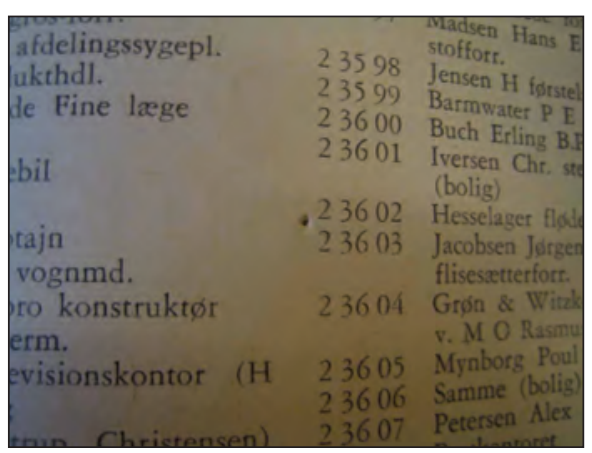

Fig. 4. Hul fra prove udtaget til pH-måling fra en telefonbog. Da vi ikke kan beskadige de originale genstande unodigt, kan der ikke laves hverken overflade-pH-målinger eller en traditionel koldekstrakt med 1 gram papir. Derfor er målingerne lavet mikrodestruktivt ved at udtage provemateriale på $1 \mathrm{~mm} i$ diameter.

håndfalsetal - altså hvor mange gange papiret kan foldes uden at knække. For at måle papirets syreindhold blev udtaget prøver på $1 \mathrm{~mm}$ i diameter (fig. 4).

Af de undersøgte genstande viste det sig, at $93 \%$ var syreholdige svarende til 1,2 millioner genstande i bibliotekets samlinger. Det vil sige, at næsten alle bibliotekets værker fra perioden 1800-1985 nedbrydes langt hurtigere end de ældre og nyere dele af samlingerne, og de udgør således en 
særlig bevaringsmæssig udfordring.

At en så stor andel af papiret i denne periode er surt og dermed har en kort levetid vil i fremtiden kunne efterlade den samlede skriftlige kulturarv med et stort hul; industrialiseringstiden i Danmark.

Allerede i dag er $8 \%$ af dette papir så nedbrudt, at det knækker, hvis det falses 3 gange, og det kan derfor ikke uden videre formidles i sin fysiske form uden risiko for at det knækker eller smuldrer. I fig. 5 ses hvor stor andelen af sprødt papir (som knækker ved op til 12 falsninger eller mindre) i Det Kongelige Bibliotek er i undersøgte årtier.

Sammenholder man papirets fysiske tilstand med papirfremstillingshistorien, så ses tydeligt en effekt af papirmaskinen og surlimningens indtog omkring 1830 og de ligninholdige fibermaterialer som halm og træ fra 1870 sammen med en mere koncentreret, sur limning og stærk benyttelse af fyldstoffer. Det er tydeligt, at samlingernes tilstand er dårligst for genstande fremstillet i 1880'erne, hvor konkurrencen $\mathrm{i}$ branchen var meget hård, efterfulgt af en forholdsvis kraftig forbedring $i$ $1890^{\prime}$ erne, for at blive gradvis bedre $\mathrm{i}$ årtierne fremover, hvor genstandene også har færre år på bagen. Dannelsen af DfP i 1889 har uden tvivl haft en stor effekt på det danske papirs kvalitet og dermed holdbarhed $\mathrm{i}$ tiden derefter.

\section{Prognose for det sure papirs levetid}

Tdag kan vi for Det Kongelige Biblioteks store samlinger for forste gang komme med en forsigtig forudsigelse omkring de papirbaserede samlingers resterende levetid, hvis de opbevares i samme miljø som hidtil (altså ved stsuetemperatur), da vi kan

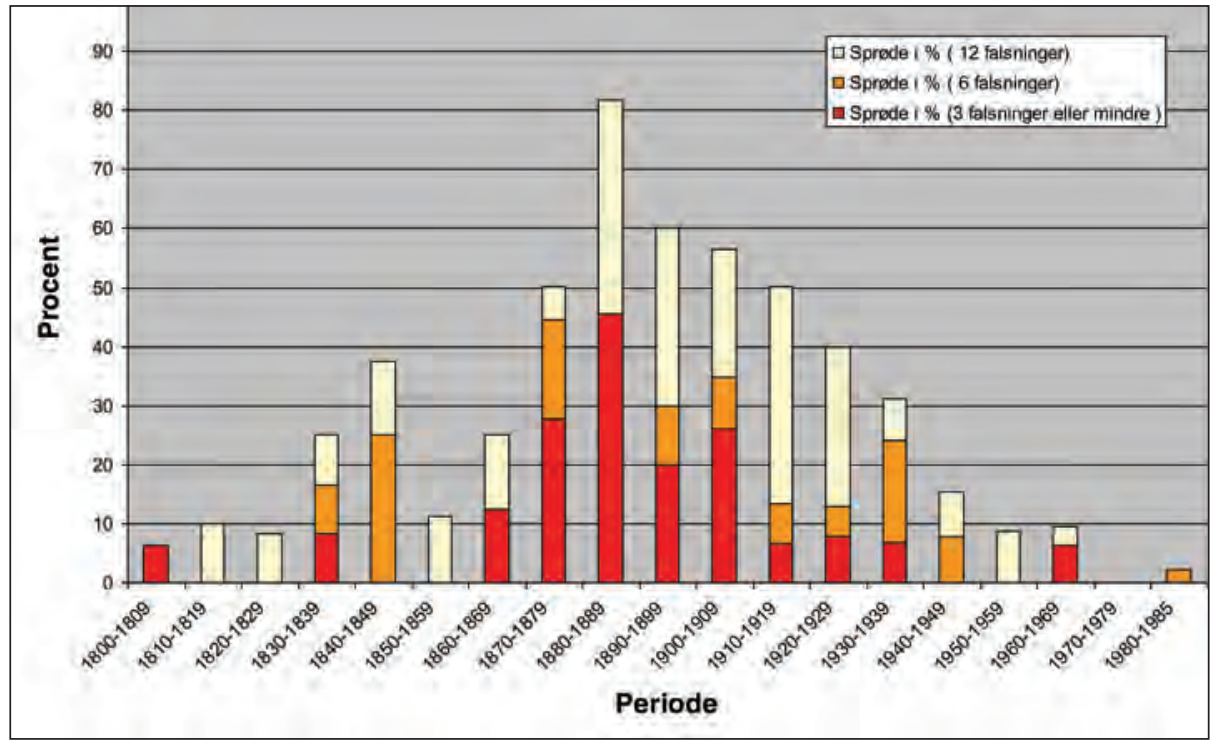

Fig. 5. Nedbrydningsgraden af de undersogte genstande fordelt på airtier i forhold til den samlede bestand af genstande fra artiet. 


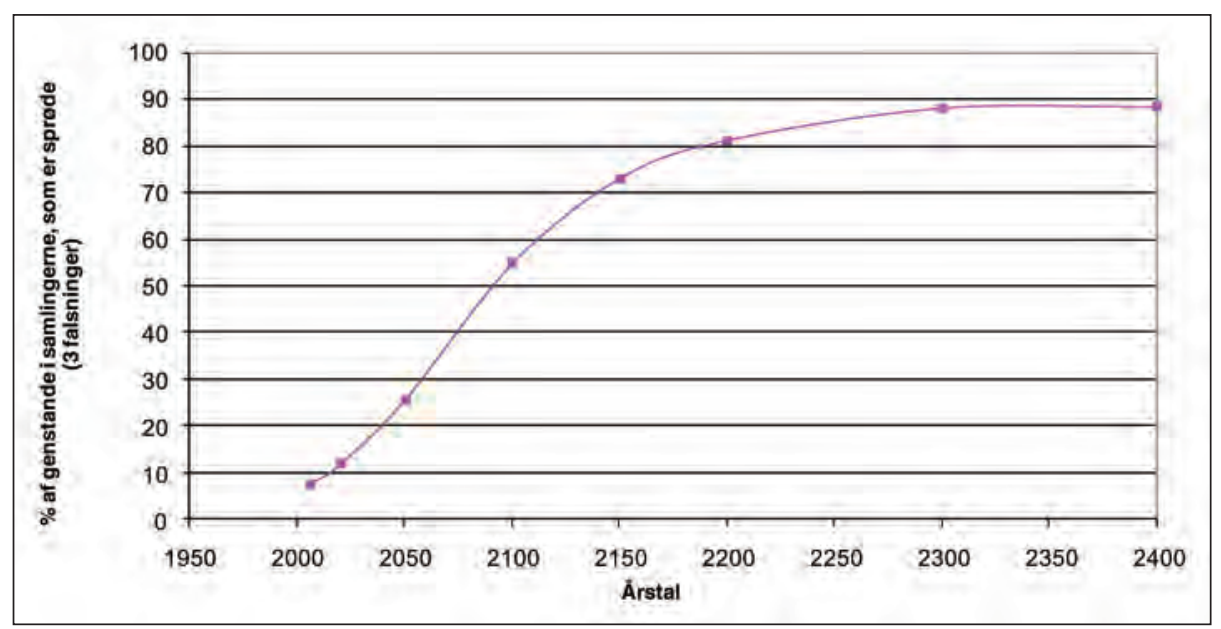

Fig. 6. Grafen viser hvor stor en del af de undersogte samlinger fra 1850-1985, der vil have nået et nedbrydningsstadium, bvor papiret knakker efter 3 falsninger, hvis de fortsat opbevares i magasiner med tempereret klima, som det historisk har varet.

sammenholde den omtalte stikprøveundersøgelses målinger af $\mathrm{pH}$-værdi- og nedbrydningsgrad med deres fremstillingsår for perioden 1850-1985. ${ }^{8}$ Det er dermed muligt at definere en sammenhæng mellem de tre faktorer og herudfra lave en prognose over de endnu ikke nedbrudte genstandes resterende håndterbare levetid, idet vi fra stikprøven kender de enkelte genstandes nuværende alder og pH-værdi.

Som det ses i fig. 6, så vil så godt som alle vores syreholdige, bevaringsværdige genstande (93\% af bestanden) om 200 år være så nedbrudte, at de vil have overskredet grænsen for at kunne tåle almindelig fysisk brug uden risiko for at det smuldrer. Sammenhængen mellem surhedsgrad og forventet levealder er sådan, at et papir med $\mathrm{pH}$ 4 kan holde i ca. 50 år og et papir med pH 5 kan holde i ca. 150 år. Størstedelen af bibliotekets papir ligger omkring $\mathrm{pH}$ 5. Det kan synes af lang tid, men set fra et konservatorsynspunkt er det ikke ret lang tid. Få materialer har historisk haft kortere levetid. Det EU-finansierede forskningsprojekt PaperTreat ${ }^{9}$ har fundet en sammenlignelig sammenhæng.

I dag møder vi kun sporadisk de meget nedbrudte genstande. Men som tiden skrider frem, vil de kommende generationer opleve en massiv nedbrydning af bøger, håndskrifter, noder, kort og billeder i biblioteker og arkiver og af deres egne bøger og dokumenter hjemme.

\section{Digitalisering, afsyring eller nedkøling \\ or at forlænge samlingernes
levetid kan vi opbevare dem
i køligere magasiner med lav} luftfugtighed og/eller masseafsyre dem. Ved masseafsyring neutraliseres syren i papiret med et alkalisk salt, og en bufferkapacitet indlejres og forebygger fremtidig forsuring. Der har i årtier 
Fig. 7. Ved masseafsyringen

hos PaperSave Swiss

i Schweiz behandles

et belt batch på en

gang $i$ en oplosning af

magnesiumtitaniumalkoxid og

bexamethyldisiloxan.

eksisteret anlæg, hvor forholdsvis store mængder surt papir kan afsyres på én gang uden håndtering $\mathrm{og}$ med få skader.

Der er adskillige metoder i brug - i fig. 7 vises blot et enkelt anlæg fra Schweiz.

I PaperTreat-projektet er effekten af masseafsyring beregnet til at give ca. tre gange forlænget levetid for papir med pH 5, som er repræsentativt for hovedparten af vores nationale samlinger.

Papirs nedbrydningshastighed påvirkes først og fremmest af temperaturen, men også luftfugtigheden (RF) i magasinerne spiller en stor rolle, da nedbrydningen er afhængig af vand/fugt. Påvirkningen er veldokumenteret, ${ }^{10} \mathrm{og}$ man kan med rimelig sikkerhed antage, at papirets levetid eksempelvis kan fordobles, hvis klimaet ændres fra $20^{\circ} \mathrm{C} / 50$ $\%$ RF til $18^{\circ} \mathrm{C} / 40 \% \mathrm{RF}$. Ved at ændre klimaet er det endda muligt at forlænge levetiden med 20 gange, hvis temperaturen sænkes til $5^{\circ} \mathrm{C}$ i kombination med en luftfugtighed på $30 \%$. Og meget længere ved nedfrysning.

En forlængelse af levetiden

med tre gange kan, som alternativ til masseafsyring, opnås ved at sænke temperatur og RF fra de typiske magasinforhold på $20^{\circ} \mathrm{C} / 50 \% \mathrm{RF}$ til $15^{\circ} \mathrm{C} / 45$ $\%$ RF. Herved er det muligt, at forlænge genstandenes brugbare levetid så meget, at kun omkring halvdelen af de syrehol- dige papirgenstande vil have overskredet grænsen for fysisk brug om 200 år. Selvom samlingerne masseafsyres, vil omkring $60 \%$ af bibliotekets genstande have overskredet grænsen om 300 år, hvis de derefter fortsat opbevares ved stuetemperatur.

Regner man på omkostningerne pr. ekstra opnået levetidsforlængelse, viser det sig, at det er langt billigere at køle ned, end det er at afsyre. ${ }^{11}$ Med dagens priser kan vi nedkøle i 180 år for samme pris som masseafsyring med en levetidsforlængelse på omkring tre. Jo mere vi køler ned - des billigere er det pr. levetidsforlængelse.

Når det bærende medium i form af papir med tiden bliver så nedbrudt, at det ikke længere kan håndteres, må vi på alternativ vis sikre, at informationen er tilgængelig. I vores digitale tidsalder er det nærliggende at sikre informationen via digitalisering. Det er dog mange gange dyrere at langtidsbevare informationen digitalt end at bevare den fysiske original. Derfor er det afgørende at forlænge den fysisk anvendelige levetid af materialet så langt som muligt og forst digitalisere for langtidsbevaring af informationen så sent som muligt.

Ud fra den nedsatte arbejdsgruppens evaluering af fordele og ulemper ved kolde magasiner frem for masseafsyring har biblioteket besluttet at arbejde for en udvidelse af kapaciteten af kolde magasiner, idet masseafsyring hverken er økonomisk eller etisk konkurrencedygtig.

Forhåbentlig lykkes det hermed at sikre den skriftlige kulturarvs 


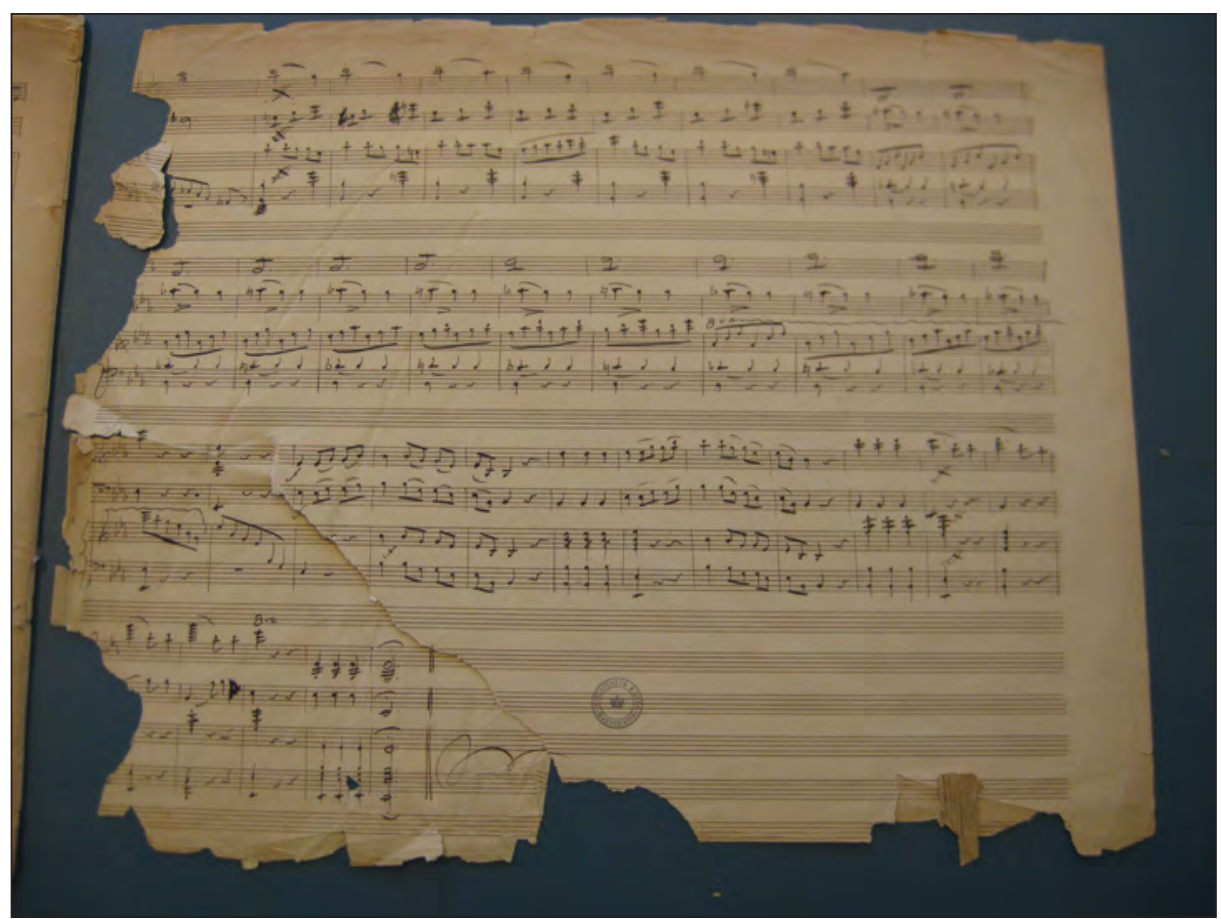

Fig. 8. Håndskrevet node på surt og sprodt papir. Sidste side af Peter Heises (1830-1879) klavertrio.

fysiske eksistens i mange generationer fremover, så biblioteket kun i begrænset omfang for de næstkommende generationer, vil være nødt til at give beskeden, at det efterspurgte materiale desværre

\section{Noter}

1 Larsen, Kjeld Dalsgaard: Dansk Papirindustri 1829-1999. 2000, s. 17.

2 Bent Schmidt, Bikuben Papirmuseet. Personlig korrespondance.

3 Dąbrowski, J., "Aspects of Technology and Market Forces in the Story of Permanent and Durable Papers." I IPH Congres-book. 15/2004, p. 117-134.

4 ANSI NISO Standard Z39.48-1984 - "Permanence of Paper for Publications and Documents in Libraries" i 1984. Siden også vedtaget som "International Standard ISO ikke længere kan benyttes.

I fig. 8 ses en af bibliotekets håndskrevne noder på sprødt papir, der ikke har kunnet holde til håndteringen.

9706:1994, International Organization for Standardization, Geneva. Information and documentation - Paper for documents - Requirements for permanence".

5 ASTM D 3290-00, "Standard Specification for Bond and Ledger Papers for Permanent Records", section 3.2.3.2 and Appendix $\mathrm{X} 1$.

6 Resultatet af arbejdet, der løb frem til 2008, kan ses i netpublikationen Bevaring af surt papir $i$ de statslige samlinger. $45 \mathrm{~s}$. Publikationen er udgivet af Styrelsen for Bibliotek 
og Medier 29. 12. 2008 på http://www. bibliotekogmedier.dk/publikationer/rapporter-fra-bibliotek-og-medier/.

7 Stikprøven bestod af 390 tilfældigt udvalgte genstande fra bibliotekets samlinger af enestående national betydning mellem $1800 \mathrm{og}$ 1985. Stikprøven havde et konfidensniveau på $95+/-5 \%$. Resultater af stikproveundersogelser udfort $i$ Det Kongelige Biblioteks og Statens Arkivers Samlinger. Det Kongelige Biblioteks Bevaringsafdeling, 2007. 34 s. findes tilgængelig på http://www.bibliotekogmedier.dk/fileadmin/publikationer/rapporter_oevrige/bilagA_Resultater_stikproeve. pdf.
8 Hansen, B.V. " En sur udfordring - om surt papir i bibliotekets samlinger". I Fund og Forskning, bind 49, 2010, s. 421-436.

9 PaperTreats hjemmeside: http://cordis. europa.eu/fetch?CALLER=FP6_PROJ\& ACTION $=\mathrm{D} \& D O C=1 \& C A T=P R O J \& Q$ UERY $=01234 \mathrm{~b} 939 \mathrm{f} 10: 0 \mathrm{fd} 7: 3 \mathrm{c} 94 \mathrm{fa} 43 \& \mathrm{RC}$ $\mathrm{N}=7592$

10 ASHRAE Handbook - Heating, Ventilating, and Air-Conditioning - Systems and Equipment, Chapter 21, 2007.

11 Hansen, B. V. "Cold storage as an alternative to mass deacidification". Artikel i forbindelse med konferencen Incredible Industry, 25.-29. maj 2009. 